\title{
Can we integrate land-use and transport planning? An investigation into the use of travel planning in regulation
}

\author{
L. Wynne \\ University of Technology, Sydney, Australia
}

\begin{abstract}
A growing interest regarding the integration of land-use and transport planning has led to the inclusion of transport planning mechanisms within land-use planning policies at the local-government level in New South Wales, Australia.

Travel planning is a site-based transport planning methodology that seeks to reduce the number of single-occupancy vehicle trips generated by a site or precinct. Many local governments in Sydney are beginning to incorporate a travel planning mechanism, which requires developers to prepare and implement travel plans for new sites, as a condition of development consent. But is this mechanism achieving its intended goal?

This research investigated the use of this mechanism in local government Development Control Plans in Sydney to explore whether these controls are effectively delivering an integration of transport outcomes in land-use planning. Through a series of interviews with local government planners from a range of Sydney councils it was found that the current legislative context in NSW is not sufficient to deliver transport outcomes via the land-use planning system. The research found that the land-use planning system is an inappropriate stage at which to include a travel planning mechanism. The paper outlines shortcomings in the use of this transport planning mechanisms in a land-use oriented legislative context, and makes recommendations for improvement of the mechanism.

Keywords: transport planning, land-use planning, travel planning, travel demand management.
\end{abstract}




\section{Introduction}

Internationally, there is growing interest among governments and planners concerning the integration of transport and land-use planning, with a view to generating better city-scale outcomes. Strategies such as integrated accessibility planning, development of mixed-use centres and transit-oriented development are among a range of methods being employed in an effort to achieve this integration. However, these models focus largely on the regional, city or network scale, and fail to recognise opportunities at the site scale. Further, such models rarely recognise the role that individual attitudes towards transport may have upon transport outcomes [1].

Travel planning is a method for integrating transport and land-use policy at the site scale. Travel planning has generated interest since the $1990 \mathrm{~s}$ as a means of reducing the impact of new developments upon transport networks [2]. Travel plans are site-based strategies developed by companies to reduce reliance on private-vehicle commuting by staff or residents of a particular site or precinct. Traditionally, the method is instigated by a company wishing to alter its staffcommuting patterns. However, Rye et al. [3] report that, more recently, travel plans have come to be included within land-use planning regulation and policy as a means of limiting the impact of new developments upon the transport system.

The use of travel planning in the development process is intended to serve three key functions. The first of these is to require the developer to consider the transport implications of a new development and to manage these at the sitescale. The second is to recognise the role that behaviour plays in influencing transport outcomes. Travel plans focus on the use of incentives to prompt behaviour change - a shift away from more traditional efforts to use spatial planning and network-scale changes to deliver improved outcomes. Thirdly, travel planning pays attention to the site scale, rather than the regional, city or network scale commonly deployed in the majority of land-use transport interaction literature.

This research focused on the effectiveness of land-use planning regulations in bringing about effective travel plans, in order to understand whether this mechanism might be a successful integration of land-use and transport policy. The research examined the appropriateness of travel planning as a land-use planning control, as well as local authorities' ability to assess, enforce and monitor these travel plans once they are created. The paper focuses on a case study of this regulation in New South Wales, Australia, however the findings will have relevance throughout many jurisdictions due to similar limitations on the resources and authority available to planning departments worldwide.

\section{The research gap}

Since the 1990s, urban planners have tried to adapt the built environment to reduce car use, and a significant amount of literature exists relating to this. However, much of this literature - including the significant body of work on transit-oriented development - focuses on the use of spatial planning to reduce 
car use, rather than examining how behaviour, attitudes and site-scale policies might provide incentives to use particular modes [1].

Rye et al. [3] note that both land-use planning and transport planning literature are relatively silent on the use of the land-use planning system to secure the implementation of travel plans, and that there are many more facets of this topic to be explored.

A few studies have been carried out to assess the effectiveness of travel planning as a development control mechanism in the US and UK contexts (including [2], [3] and [4]) and these are discussed further in Section 4. However, very few papers (except [5] and [6]) have been written regarding the Australian context, despite increasing inclusion of travel planning as a regulatory measure.

This research responds to a need to investigate the effectiveness of travel plans required under land-use planning law in the Australian context. Further, it examines whether institutional and policy barriers are preventing the development and implementation of effective travel plans, and whether opportunities exist to improve the effectiveness of these mechanisms.

\section{Case study: Sydney, New South Wales}

Sydney, the major metropolitan area of NSW, is home to 4.6 million people. Sydney suffers from a high level of dependence on private-vehicle transport $-\mathrm{Xu}$ and Milthorpe [7] report that $71 \%$ of all journey-to-work trips are taken by private vehicle, resulting in congestion that costs Sydney an estimated $\$ 5.2$ billion per year. Authorities have an urgent need to alter transport patterns and shift mode-share away from single-occupant private-vehicle trips to public and active transport modes.

\subsection{The NSW land-use planning system: LEPs and DCPs}

Land-use planning in NSW is regulated and implemented at two levels -state and local. The NSW Department of Planning makes strategic decisions to determine the direction of land-use planning state-wide, while local governments prepare local strategic plans, and assess and approve development applications.

NSW local governments undertake strategic planning and regulate development through two key mechanisms - Local Environmental Plans (LEPs) and Development Control Plans (DCP). LEPs are legal instruments prepared by each local government to impose standards to control development such as zoning maps and floor-space ratios. DCPs are non-legal documents that support a local government's LEP with more detailed planning and design guidelines.

\subsection{Transport planning in NSW}

Responsibility for transport planning in Sydney rests, in the main, with the NSW state government, which funds and makes decisions regarding public transport infrastructure and major/regional roads. Sydney's local governments are responsible for policy and operational decisions relating to local roads, footpaths and public transport facilities (e.g. bus stops), parking and developments. 
This division of responsibilities can be problematic - despite having decisionmaking ability regarding land development, local governments are unable to control the transport infrastructure that will service such developments.

Perhaps in response to this, local governments are increasingly including transport objectives within their strategic land-use planning. Specifically, many are beginning to include a requirement in DCPs that developers who submit applications for developments that exceed a set threshold must prepare a travel plan. However, travel plans are a relatively novel concept in NSW planning policy and - despite a growing number of councils beginning to include these requirements - few policies provide guidelines to assist developers in creating their travel plans, monitoring measures to track the effectiveness of implementation or the impact of the development, or enforcement mechanisms to ensure that the travel plans are implemented once the development is built.

Travel plans are also known as 'travel demand management plans' or 'mobility plans'. For consistency, the term 'travel plan' is used exclusively here.

\section{The literature}

Curtis and James note that, historically, there has been a tradition of separating land-use and transport planning functions [8]. This separation has severed transport policies, departments and ministers from land-use functions, meaning the two areas were developed largely in isolation. This began to change in response to Newman and Kenworthy's work in the 1980s, when they began publishing evidence that linked spatial planning characteristics to trip generation, and made a case for integrating transport and land-use planning [9]. This was part of a growing awareness that cities needed to implement transit-oriented development to address the car dependency that was choking cities around the world.

The transport land-use integration literature recognises that land-use type determines the activities that take place in a locality, which in turn determines trip generation [10]. Most models in the literature attempt to typify or categorise spatial planning patterns and describe their relationship with transport outcomes. However, as noted by Wegener and Furst [10], mainstream land-use transport interaction theory adopts a restricted, engineering-based perception of the urban system as a system of movements. Apart from the literature on travel planning, few models focus on the site-scale policies and incentives that might be generated at the site level in order to produce improved transport outcomes. The following section discusses how the literature has specifically addressed travel planning.

\subsection{Historical overview of travel planning}

Travel plans have been used in Europe - especially the UK - and the US to facilitate the uptake of transport options that provide alternatives to privatevehicle ownership and use [12]. Enoch and Ison [2] note that travels plans have their origins in the US, where they arose in response to the 1970s oil crisis in recognition of the need to reduce reliance on single-occupant vehicle commutes. 
Travel plans involve collecting data on travel patterns, setting targets to reduce reliance on private vehicles, and developing and implementing actions to achieve these targets. Enoch and Ison [2] describe them as typically including a mix of incentives for the use of sustainable transport modes and disincentives for the use of single-occupant private-vehicle commuting, and a mix of both 'soft' (e.g. policy) and 'hard' (e.g. infrastructure) measures.

Enoch and Ison [2] refer to several site-level studies in the UK which have shown that the implementation of travel plans has resulted in a reduction in single-occupant vehicle commutes of between 15 and $30 \%$, with the UK Department for Transport [12] citing other studies eliciting reductions as high as $66 \%$. Other studies, which also cover European and US examples [2, 7], have shown great variability in impacts. It is not clear from the literature whether the above figures relate to travel plans which were prepared voluntarily or whether they were required by regulation.

Despite these reported successes, the uptake of travel plans has been shown to be relatively low where travel planning is a voluntary requirement and, as Roby [11] reports, an organisation's motivation for instigating a travel planning process will rarely be due to a commitment to corporate social responsibility or to reduce congestion. Rather, the impetus to develop a travel plan is more often due to a compulsion or requirement by another authority.

\subsection{Travel planning and land-use planning law}

Perhaps in response to this low uptake of voluntary travel planning, local authorities in the UK have begun to require travel plans to be prepared and implemented by developers as part of the development approval process [2]. This was accelerated after the 2004 release of the 'Smarter Choices' agenda by the Department of Transport, which argued for 'soft' measures as a complement to 'hard' infrastructure solutions to congestion problems [2]. The ultimate objective of this move is to ensure that new developments are accessible by a range of transport modes, and do not create undue stress on existing transport infrastructure [3]. These statutory requirements are the impetus behind the majority of travel plans, with $75 \%$ of all travel plans in the UK secured through the planning system rather than through voluntary uptake [2].

However, development controls and planning agreements are not designed for transport-related measures, which complicates the associated assessment and compliance processes, and makes it difficult for local authorities to secure results [2]. Enoch and Ison [2], Rye et al. [3, 4] identify several major issues with the use of development controls to ensure travel planning - the quality of the planning, the implementation and monitoring of the actions, and the local authority's ability to enforce the plan. The following section will discuss these issues and barriers.

\subsection{Major barriers to travel planning effectiveness}

The literature identifies a number of major barriers to the effectiveness of travel planning, particularly from on UK examples. Barriers include: 
- Many developers do not know how to develop a travel plan as they are unaccustomed to dealing with transport planning [2].

- Very few local authorities provide adequate guidance to develop an effective travel plan [3].

- Travel plans require significant human resources and program-planning assistance as well as ongoing support such as workshops and guidance [5].

- Developers tend to regard the travel planning process as a 'tick-box' exercise, approaching the travel plan as a document to be submitted as part of the development application process, rather than as a commitment to implement the actions listed within [3].

- Many planning assessment officers are not equipped with the knowledge or tools to assess the quality or effectiveness of travel plans which are submitted [2].

- Few local authorities specify a requirement for target-setting as part of travel plan development, nor do they place an obligation on developers to outline how implementation and the impact of the plan will be monitored [3]. This is despite target-setting and monitoring both being identified throughout the literature as crucial components of the travel planning process [13].

- A standardised approach to monitoring the impacts of travel plans is needed to allow councils to evaluate the quality or implementation of travel plans [3].

- Local authorities have no ability to enforce the implementation of the actions identified in travel plans remains a significant weakness in the use of the land-use planning system. Many local authorities surveyed as part of a study by Rye et al. [3] identified that they were not sure how they would go about enforcing the commitments made by a developer.

- No legal cases relating to travel planning have been tested in court in the UK, meaning local authorities are uncertain about the extent to which they will be able to enforce travel plans [2].

\section{Methodology}

This study undertook a detailed document analysis of Sydney local DCPs and interviewed a range of relevant stakeholders to understand the issues arising when travel plans are included in the development application process. The original intention of the work was to review monitoring and evaluation data from local governments to understand the impact that travel plans were having upon trip generation, however a complete lack of relevant data prevented such a study.

This methodology follows Rye et al. [3] who conducted interviews with council planning officers to understand the barriers to effective travel planning in the UK planning context.

A document analysis investigated how many councils are including travel plans as part of their DCPs, and what kinds of controls and guidelines are associated with these. The analysis considered the extent to which guidelines, monitoring and enforcement mechanisms were included. 
25 DCPs from a varied sample of 21 Sydney councils were reviewed, with a broad geographic coverage and including a range of large and small councils. 21 DCPs were reviewed, as well as three draft DCPs and one area-specific DCP for a precinct. The DCPs included councils from various geographical areas of Sydney and represented councils of various sizes, including all four major CBD councils - City of Sydney, Parramatta, North Sydney and Willoughby.

The study also involved semi-structured interviews with planning and transport officers from four metropolitan Sydney councils, and the Transport Manager of Optus - a site which was involved in the travel planning process as a condition of development consent. These interviews sought to find out whether the development approval process is an appropriate point for travel planning to be required, to uncover some of the specific barriers to travel plan implementation and to understand whether travel plans developed through the development application process could be effective.

\section{Results}

This chapter will outline the results of the research undertaken for this study. The first section will describe the findings of the document analysis, and will be followed by the findings of the interviews.

\subsection{Document analysis}

The DCPs of 21 Sydney councils as well as three draft DCPs - which were not yet adopted - were analysed. A local-area DCP was reviewed also. With only one exception, those DCPs that included a travel planning requirement had all been approved and implemented within the last two years, suggesting that the trend for including travel planning is a relatively recent one.

This review analysed the DCPs to understand whether they include adequate requirements to facilitate successful travel planning. In short:

- Five of the 25 DCPs contained a travel-planning requirement, and a further three councils had a requirement for travel planning in draft DCPs.

- Four DCPs included only links or references to other guidelines as guidance for the developer, while another two included just a few examples of possible actions as guidance. The remainder provided minimal guidance such as a description of the aims of travel planning or the types of strategies that could be considered.

- Seven of the nine DCPs clearly articulated a requirement to set targets for achieving particular mode-shares and for reducing single-occupant vehicle travel. There was no guidance provided regarding how ambitious these targets would need to be.

- Four of the nine DCPs specify the enforcement mechanism that will be utilised to require implementation of the travel planning. The remainder of DCPs are unclear with regards to required enforcement mechanisms. 


\subsection{Interviews}

The interviews uncovered a variety of different views on the inclusion of travel planning in DCPs. This section discusses the interview findings, grouping them according to key themes which emerged throughout the discussions.

\subsubsection{General comments}

- All interviewees noted that travel plans are useful mechanisms when applied in the right circumstances. However, several of the interviewees argued that the development application and approval process is not the appropriate place for travel plans, and noted that travel plans are 'not something you can force on people'.

- Several of those interviewed, including the developer, noted that travel planning would be most effective if required uniformly across a region or precinct. This would allow adjacent sites to cooperate and share resources, and jointly lobby for improved services, access and amenities.

- It was noted that the process of determining the threshold size at which travel plans are required was 'extremely arbitrary'. Most DCPs use employee numbers and numbers of residential units as a trigger to determine which developments will be obligated to submit a travel plan.

\subsubsection{Appropriateness of land-use planning decisions as the point of intervention}

A recurrent theme throughout all the interviews concerned whether or not the development approval process is an appropriate point for a travel plan to be required.

Travel plans were described by an interviewee as being 'human resources plans conscious of there being alternatives to private vehicles'. In other words, travel plans are primarily about people and their travel behaviour - often referred to as 'soft measures', rather than about the 'hard measures' such as facilities and infrastructure. In a development context, travel plans relate to the activities of the occupants of the building - not the developers. However, the development approval process very often occurs before occupants are identified - meaning that travel plans submitted with a development application will not be prepared with specific tenants in mind.

Further emphasising this point, several interviewees noted that the (few) examples of successful travel plans in the Sydney context have been instances where the tenant was known to the developer - such as the case of Optus, in which Stockland developed a purpose-built campus for them - or where the developer was to occupy the building. Interviewees noted that without connections with the occupants of the building, a travel plan cannot deal with the 'soft measures' that will act to change the travel behaviours of the occupants.

Finally, without knowledge of the occupants and their travel patterns, establishing credible baseline data is an almost-impossible task. 


\subsubsection{Development of quality travel plans}

The interviews revealed that councils have significant doubts about the quality of travel plans likely to be submitted through the development application process. The fact that travel planning (or transport in general) is highly unlikely to be the core business of the developer or occupier was identified as a major reason for the submission of inadequate or inappropriate travel plans.

A quality travel planning process should involve engagement with both senior management and staff at all levels of the organisation to which it will apply. Interviewees noted that if the occupant is not identified at the development stage, then developing a quality travel plan at this stage will be near impossible due to the associated inability to engage with senior management or understand occupant travel behaviours and patterns.

One of the council transport planners noted that unless developers are encouraged to see the value in developing a travel plan, they are unlikely to devote time and resources to developing a quality travel plan. It was emphasised that if councils should provide guidance to developers to help them see the potential benefits of a travel plan.

DCPs tend to provide little guidance for developers regarding what a travel plan should be and how to develop one. Several of the interviewees noted that the fact that travel plans are currently relatively undefined by DCPs is a concern council assessment officers have little guidance about assessing travel plans, and the lack of definition will make the requirement difficult to hold up in court due to uncertain requirements.

\subsubsection{Assessment and monitoring}

Assessment and monitoring were identified throughout the interviews as recurrent concerns. One of the interviewees argued that the biggest question in regards to travel planning is the question of monitoring.

Firstly, a lack of monitoring provisions within the regulation - and an inability to incorporate any such provisions - was identified. None of those interviewed could identify a meaningful and effective way to incorporate monitoring requirements into the obligations of the DCP. Prescription of targets for mode share was identified as a possible means of providing a benchmark against which achievements could be monitored, however selecting a target was noted to be a difficult (and inevitably, arbitrary) process - an enforcing compliance with such a target is likely impossible.

Secondly, resources for pursuing any kind of adequate assessment or monitoring are significantly limited. Generally, NSW councils are pressured to keep their development application processing times as short as possible, and staff are already overwhelmed with work. Adding an extra requirement to monitor travel plans would not be well received. Compounding this is the fact that few development assessment staff are adequately informed about travel planning, and thus would not be in a position to assess or monitor travel plans.

Additionally, the travel planning process does not fit within the normal time frame of development assessment processes. Generally, the development process concludes with the issuing of an occupation certificate - prior to the building being inhabited. Any further matters are dealt with as compliance issues. Travel 
planning should, however, be an ongoing and continual process of review and implementation. Interviewees noted this means that it does not sit well with the usual duties of council assessment planners.

Thirdly, the monitoring and evaluation process remains almost entirely unclear. Interviewees noted that no responsibility is assigned within council for assessing whether the plan has been implemented, and no ongoing monitoring strategies or reports are requested.

\subsubsection{Enforcement}

Councils' inability to enforce the travel planning requirement was also raised as a problematic component of the mechanism throughout several interviews. Significant doubts were raised regarding whether the travel planning requirement could be upheld in court - no cases have been brought to court relating to this mechanism, and several interviewees expressed concern about the ability to uphold the requirement. Two council staff who were interviewed noted that they were unwilling - and most likely also unable - to force developers to implement the actions and strategies of their travel plan. Indeed, one interviewee noted that weak enforceability meant that his team of assessment officers were not likely to stop a development happening due to a poor quality travel plan.

The issue of enforceability is a complex one - councils cannot usually place a condition of development consent upon the tenants of a building, as their jurisdiction in this area is limited to development and land use. Therefore, they are unable to enforce the implementation of travel planning beyond anything that is installed by the developer at the initial construction stage.

An additional problem was noted to be that it would become very difficult for councils to demonstrate that a developer had breached the conditions of consent even if such a breach was within their jurisdiction. Establishing any such targets or benchmarks against which compliance or non-compliance could be measured (such as a mode-share target) would be extremely difficult, as determining targets for travel planning is generally very site- or organisation-specific.

\section{Discussion}

The single most significant issue arising throughout this investigation related to whether DCPs are an appropriate point at which to oblige travel planning.

Given that -

1. Councils cannot expect developers to implement actions that relate to elements that are outside their realm of control such as tenant's human resources policies;

2. Tenants are the only party who would be able to implement actions such as internal policy changes; and

3. Councils cannot place a condition of consent upon a tenant;

- it becomes difficult to understand how councils could possibly force implementation of any 'soft' measures described in a travel plan.

Interestingly, this issue arose far less through the UK-centred literature than it in this study of the Australian context. This is perhaps a result of differences in 
planning systems between Australia and the UK. Understanding differences in the UK and Australian experiences in the use of travel planning as a development control presents an interesting avenue for future research.

It is impossible to force developers to create effective travel plans in the NSW context as they are unable to control crucial elements of the site's operations that will influence travel behaviour. This is not necessarily due to an unwillingness to undertake travel planning on the part of the developers, but rather due to the very nature of travel planning involving elements that are likely out of the developer's control - travel planning requires knowledge of the occupants of a building or site, and an understanding of their travel patterns and the motivating factors underlying this behaviour. Without the ability to gather baseline data by monitoring the pre-travel plan habits of the occupants, the process of setting targets and selecting actions becomes an arbitrary one.

Further, the developer's ability to influence the 'soft' side of the travel planning process is extremely limited, as the developer is rarely the occupier and is unable to influence the behaviour of tenants or the policy of the tenant organisation. Developers could choose to make the implementation of the travel plan a condition of the lease, however would still most likely find it difficult to require changes to internal human resources policy (such as the provision of fleet cars or parking spots). The travel planning process needs to be undertaken at a point at which the behaviour of the occupants can be understood and influenced. Rarely is the development approval process going to be a point at which this is possible, nor will the developer be in a position to do so.

Guidance provided in DCPs to assist developers to prepare travel plans is currently quite limited. Myers [6] stressed the importance of providing developers with clearly understandable guidelines, it would seem this is a crucial element missing from DCPs at present, and may be a component which, if improved, could help developers to create better travel plans. This research found that an inability to assess travel plans was a major stumbling block for councils.

Monitoring of outcomes has been identified as a major issue throughout the travel planning process. It was found that most DCPs do not adequately demand monitoring and reporting so as to ensure that councils are kept informed about developers' progress in implementing the plans. A lack of monitoring, data collection and reporting requirements will mean that neither the developer nor the council understands whether they are making progress towards targets set in the travel plan.

Enforcement and compliance is a critical weakness of the travel planning requirement in DCPs. This was found to be a major reason why some councils are choosing not to include a travel planning requirement in their DCPs - a finding echoed throughout the literature [3].

Enforcement of the travel plan is complicated by councils' inability to place a condition of consent upon a tenant. Tenants are more often the party who would be in a position to implement many of the key 'soft' actions of a travel plan, such as changes to human resources policies and implementing behaviour change programs. Councils may require developers to implement 'hard' measures such as bicycle facilities, however their inability to influence the tenant's internal 
operations and policies means that none of the 'soft' measures relating to human resources policies and behaviour change programs are enforceable.

\section{Conclusion and recommendations}

This research has undertaken investigations to determine whether the travel planning requirement in NSW local government DCPs is likely to result in effective outcomes. While focused on the NSW context, the findings have relevance for other jurisdictions that are considering using travel planning mechanisms to integrate transport and land-use planning.

Overall, the findings of this research have indicated that travel planning - at least in this context - is not likely to deliver a successful integration of transport measures into land-use planning regulations. This research found that the development application and approval process is not the appropriate point at which to require travel planning, as it places the responsibility on a party who is unable to control many elements of the process which would be required to successfully implement a travel plan. The major recommendation of this report is that travel planning requirements should be removed from DCPs, as in its current form it represents only an unnecessary regulatory burden upon developers, without proof of sustainable outcomes. An inability to monitor and enforce the requirement, coupled with the fact that developers are the inappropriate party upon which to place a travel-planning responsibility, means that the obligation is unlikely to result in effective travel plans.

A number of recommendations have been developed which outline how the existing policy and mechanism could be improved. While these do not address the concern about whether DCPs are appropriate intervention points, major improvements which could assist implementation and effectiveness are:

1. Clearer guidelines to assist developers to understand what travel planning is, what is required of them and what the travel planning process involves - including data and monitoring requirements;

2. Information should be given to developers to outline what the potential benefits of travel planning are, in order to help them understand why the requirement exists;

3. Guidelines for assessment officers at local governments to allow them to use a standardised process to assess the quality and plausibility of travel plans submitted as part of the development application process;

4. Stronger requirements for reporting and monitoring to allow councils to track whether developers are complying with the requirement.

Travel planning requirements might be appropriately included as conditions of consent where significant opportunities are identified by councils - such as in those rare cases where the developer is also the occupier of a site, or where a site it being developed for a particular tenant. Allowing the travel planning requirement to be invoked at the discretion of council when appropriate opportunities are identified - rather than more broadly to all developments over a particular size - will create a reduced assessment, monitoring and enforcement 
burden for councils, and will ensure that the travel planning burden is only placed on developers in instances where it is likely to be effective.

\section{References}

[1] De Vos, J., Van Acker, V. and Witlox, F. The influence of attitudes on Transit-Oriented Development: An explorative analysis. Transport Policy, 2014.

[2] Enoch, M. \& Ison, S. Mainstreaming travel plans in the UK: Policy proposals for Government. Research report to the Department for Transport and the National Business Travel Network, 2008.

[3] Rye, T., Green, C., Young, E. \& Ison, S. Using the land-use planning process to secure travel plans: an assessment of progress in England to date. Journal of Transport Geography, 19(2): 235-243, 2011.

[4] Rye, T., Welsch, J., Plevnik, A. \& De Tommasi, R. First steps towards cross-national transfer in integrating mobility management and land use planning in the EU and Switzerland. Transport Policy, 18(3): 533-543, 2011.

[5] Meiklejohn, D., \& Wake, D. A Tale of Two Cities: Workplace Travel Plan Programs in Melbourne and Perth. Proceedings of the $30^{\text {th }}$ Australiasian Transport Research Forum, pp. 1-10, 2007.

[6] Myers, K. Travel Behaviour Change Initiatives: A Local Government's Innovations. Proceedings of the $28^{\text {th }}$ Australiasian Transport Research Forum, 2005.

[7] $\mathrm{Xu}, \mathrm{B}$ and Milthorpe, F. Analysis of Journey to Work Patterns in Sydney. Proceedings of the Australian Transport Research Forum, 2010.

[8] Curtis, C. and James, B. An institutional model for land use and transport integration, Urban Policy and Research, 22(3), 277-297, 2004.

[9] Newman, P. and Kenworthy, J. Cities and Automobile Dependence: An International Sourcebook Gower, Aldershot, UK, 1989.

[10] Wegener, M. and Furst, F. Land-use transport interaction: State of the art. Report for the TRANSLAND project, 1999.

[11] Roby, H. The development of workplace travel plans. Proceedings of the Universities Transport Study Group Conference, 2009.

[12] UK Department for Transport. Making travel plans work: Lessons from UK case studies, 2002.

[13] NSW Department of Planning. A guide to preparing local environment plans, 2009. 